\title{
Nutritional Profile and Socio-Economic Status of Saharia, a Primitive Tribe of India
}

\author{
Satwanti Kapoor*, ${ }^{*}$, Renu Tyagi ${ }^{1}$, Kiran Saluja ${ }^{1}$, Anumeha Chaturvedi ${ }^{1}$ and A.K. Kapoor ${ }^{2}$ \\ ${ }^{1}$ Department of Anthropology, University of Delhi, Delhi-110007, India \\ ${ }^{2}$ Department of Anthropology, Jiwaji Univeristy, Gwalior- 474011, MP, India
}

\begin{abstract}
A study was conducted among Saharia, a primitive tribe of central India, with an objective to assess the nutritional profile and associated socio-economic factors. A cross sectional sample of 364 adult males and females aged 18-60 years was studied. Stature, body weight, skinfold thickness, circumferences, fat percent, grip strength and blood pressure were measured on each subject. Body mass index, Trunk extremity ratio and Grand mean thickness were computed statistically. A higher percentage of chronic energy deficient (CED) males and female subjects indicated a poor nutritional status of Saharias. A few overweight males were also found. More females were found to be undernourished than males as per the cut off values of MUAC. All the subjects were found to have normal blood pressure with the exception of a few hypertensive cases among males in overweight category. An influence of changing life style among Saharia males was more noticeable.
\end{abstract}

Keywords: Saharia, Primitive tribe, Nutritional status, Gender, SES.

\section{INTRODUCTION}

There is a consensus that the health status of the tribal population is very poor and worst among the primitive tribes because of their isolation, remoteness and being largely unaffected by the developmental processes going on in the country. The tribal population is at a higher risk of under nutrition because of their dependence on primitive agricultural practices and irregularity of food supply. Health is a prerequisite for human development and is an essential component for the well being of the mankind. The health problems of any community are influenced by interplay of various factors including social, economic, biological and political ones. Nutritional status of a population is an important tool to study health of any population. Nutritional status of the population largely depends on the consumption of food in relation to the need and requirement. Some of the studies showed a relationship between the tribal eco-system and their nutritional status $[1,2,3]$. Nutrition has been found to be associated with many morbidity conditions and mortality as well [4]. Malnutrition was found to be one of contributing factors for high or low mean age at menarche [5]. Mortality and BMI as an indicator of nutritional status exhibited $\mathbf{U}$ or $\mathbf{J}$ shaped relationship [6].

\section{AREA AND PEOPLE}

Saharia tribal groups are acquainted as a very widespread 'Kolarian'tribe [7]. The early history of origin of Saharia is not exactly clear till now. Etymological point of view expresses that the word 'Saharia' is the combination of two independent words like "Sa' (companion) and 'Haria' (tiger) which means companion of tiger [8].

*Address correspondence to this author at the Department of Anthropology, University of Delhi, Delhi -110007, India; Tel: 011-27667329 ext 230;

Fax: 011-27666614; E-mail: satwanti@yahoo.com
Saharia has been listed under the PTGs by Government of India 1975-76. In order to ensure the development of tribal communities, certain groups were identified for the first time in 1975-76 and thereafter in 1993, who are regarded as the poorest of poor amongst the Scheduled Tribes and were called Primitive Tribal Groups (PTGs). The criteria fixed for identification of such PTGs are:-

(i) pre-agricultural level of technology;

(ii) very low level of literacy; and

(iii) declining or stagnant population.

75 tribal communities were identified as PTGs spreading over 17 States and one UT. (source: Standing Committee on Labor and Welfare, 2002, Ministry of Tribal Affairs, development of PTGs $28^{\text {th }}$ report).

Traditionally, the Saharias pursue their indigenous sociocultural rules, customs and norms which affects their maternal health care system [5]. Saharias suffered due to land alienation and rehabilitation. They traditionally practiced shifting cultivation, hunting, gathering, pastoralism, etc. and sometimes also adopted nomadic quit [9]. They have quit their traditional activities due to deforestation, consistent shortage of rainfall, limited resources etc. In the present time, most of the Saharia have become daily wage earner instead of their traditional way of occupation [10]. It is a transition phase for them, wherein a handful of powerful people got mingled with the neighboring main stream groups, moved up in the political and occupational hierarchy and some even got jobs, however, the masses remained poor. These poor were left with no traditional occupation but are forced to work as landless laborers and daily wagers.

Bread is considered as their staple food. However, sometimes, due to unavailability of wheat, they consume roots, tubers, leaves, etc. which are collected from the nearby dwindling forest. Due to poor economic conditions, most of 
the Saharias cannot afford to take two square meals a day. Alcohol consumption and smoking constitute a part of their regular diet. The beverages are traditionally home brewed for their own consumption, as well as entertaining their guests. Even during pregnancy period, most $(62.8 \%)$ of the women smoked and consumed alcohol [11].

Most of the Saharias are dominated by nuclear families. Saharias are strictly clan exogamous and tribe endogamous. They generally practice negotiation and monogamy form of marriage at very early age. Divorce among Saharias is very rare. Literacy rate of Saharia is 23.2 percent, whereas 28.2 percent and 17.7 percent are for males and females respectively [12].

Among the Saharias, maximum deaths occurred due to pneumonia, malaria, tuberculosis, gastric problems, diarrhea etc. Low standard of living, poor food habits, hard work, malnutrition, insanitation, lack of purified drinking water, low level of socio-cultural status, unfavorable environment etc. are attributed reasons of such diseases [13,14]. Due to poverty, illiteracy, socio-cultural rules and regulations, inadequacy of government health center, etc., their traditional healers are initially given preference for the treatment of their diseases. In case of failure of traditional treatment, they generally come under the treatment of modern doctors.

Health of a community is better judged by the maternal care among that community. Among the Saharias special attention to diet is not provided during the pregnancy period of most women. They consumed locally available seasonal vegetables but rarely fruits. Poor maternal care may be attributed to low educational status, high extent of poverty, inadequate modern health care facilities, non-admixture with modern society and abode in a remote geographical areas [5]. To rescue from extreme labor pain, a major group of expectant mothers observed fast occasionally (90.7 percent) to please spiritual power, etc. Saharias follow lot of sociocultural rules and regulations.

In the seven Saharia villages studied, the sources of purified drinking water were totally unavailable. They were dependent on the water from wells and tube wells for both their drinking and other purposes. These villages are connected with other villages through the undulating footpath. Most of the Saharias were landless and they mostly were engaged in primary sector as wage earners. 'Anganwari' was found to be running in one of the village, Kalotra, where iron tablets were given to pregnant females. Most of the houses visited were kuchha mud house except very few pucca semi concrete houses. There were open drainage in all villages. All the houses were electrified but the electricity was available for 6-8 hours only in a day and supply was central to village. Majority of the subjects worked as laborer in kiln, roadside construction, agricultural field etc. Maternal health care was very marginal among them. Despite incentives by the Government for hospital deliveries less than 20 percent females delivered their babies in the hospitals. Majority of the deliveries were assisted by either Dai (local female health worker) or the eldest female of the household.

\section{METHODOLOGY}

The present study has been conducted among Saharias of seven villages in Shivpuri and Gwalior districts of Madhya Pradesh, namely Bhattapur, Ghategaon, Kalotra, Mandopur,
Sonipura, Dulara and Bhojpura. Before starting the field work an imperative and suitable research design was made ready. By using anthropological tools and methods, with the help of in-depth interviews and genealogies their descent was traced to the Saharia tribe.

A set of questions were administered to all of them which revealed similar behavorial practices - life style pattern, eating habits and daily habitual activities. They are an endogamous group marrying with the Saharias of nearby villages but of different clan.

The field work was conducted from October, 2007 to April 2008. A total of 380 subjects including males and females ranging in age 18-60 years were studied. Out of which, twelve subjects were excluded from final analysis as 3 females and 2 males had tuberculosis and 7 subjects could not provide complete information. Four males were further omitted as they were found to be non-Saharia. That made the total sample as 364 (males, $n=168$ and females, $n=196$ ). Information regarding personal details like age, occupation, and educational status were obtained from all subjects with the help of a structured proforma. Exact age recording was very difficult as majority of males and none of the females studied knew their date of birth. It was equally difficult to record the age at menarche and menopause. Majority of the subjects were illiterate and very low-wage earning manual laborers of low socio-economic status.

All experiments were performed in accordance with relevant guidelines and regulations. The research described was compliant with basic ethical standards. Ethical clearance was obtained as per rules and informed consent was obtained from each subject who volunteered. Necessary permission was obtained from the local community leaders, as well as relevant authorities prior to start the study.

All anthropometric measurements were taken by trained anthropologists using standard techniques of Weiner and Lourie [15]. Stature, body weight, circumferences and skinfold thickness were recorded to the nearest $0.1 \mathrm{~cm}, 0.5 \mathrm{~kg}$, $0.1 \mathrm{~cm}$ and $0.2 \mathrm{~mm}$ respectively. Body circumferences and skinfold thickness were measured using flexible steel tape and Harpenden skinfold calipers respectively. The grip strength was taken using a hand grip Dynamometer to the nearest $0.5 \mathrm{~kg}$. Blood pressure both systolic and diastolic was measured with the help of Sphygmomanometer and Stethoscope. The percent body fat was recorded using a body composition analyzer employing bioelectric impedance technique.

Body mass index (BMI) was computed as weight $(\mathrm{kg}) /$ height $(\mathrm{m})^{2}$. Nutritional status was evaluated using internationally accepted World Health Organization BMI guidelines [16]. The cut off values for BMI used to assess the nutritional status are: BMI <16.0 (CED III); $\mathrm{BMI}<16.0-16.9$ (CED II); $\mathrm{BMI}<17.0-18.4$ (CED I); BMI= 18.5-24.9 (Normal) and BMI> 25 (overweight).

Undernutrition and hunger has always formed mandate of FAO [17]. World Health Organization's [16] classification of the public health problem of low BMI, based on adult populations worldwide was followed. This classification 
Categorizes prevalence according to percentage of a population with $\mathrm{BMI}<18.5$ :

1) Low (5-9\%): warning sign, monitoring required.

2) Medium (10-19\%): poor situation.

3) High (20-39\%): serious situation.

4) Very high $(\geq 40 \%)$ : critical situation.

Mid upper arm circumference (MUAC) has also been found to be a potential screening tool for assessing nutritional status in adults [18]. In the present study, nutritional status of Saharia was also evaluated following the internationally accepted standard cut-off point of MUAC [19]. The following cut off value was used:

Undernutrition: MUAC $<22.0 \mathrm{~cm}$

Normal: MUAC $>=22.0 \mathrm{~cm}$

Trunk extremity ratio (TER) was taken as the ratio of sum of subscapular skinfold thickness and suprailiac skinfold thickness to sum of calf skinfold thickness and triceps skinfold thickness.

Grand mean thickness (GMT) was calculated as the sum of skinfold thickness (biceps+ triceps+ suprailiac+ subscapular+ calf posterior+ abdomen) divided by number of skinfold site.

The subjects were classified in different blood pressure categories according to the JNC VII [20]. The normal blood pressure was taken as $<120 \mathrm{mmHg}$ (Systolic) and $<80 \mathrm{mmHg}$ (Diastolic). Blood pressure values of 120-139 mmHg (Systolic) and $80-89 \mathrm{mmHg}$ (Diastolic) were taken as prehypertension, and hypertension was taken as more than 140 $\mathrm{mmHg}$ (Systolic), and more than $90 \mathrm{mmHg}$ (Diastolic).

The data was analyzed using SPSS 10.0 version. Mean and standard deviation were calculated for different anthropometric, physiological functions and adiposity indices.

\section{RESULTS}

Table 1 displays distribution of various socio-economic characteristics. Eighty seven percent of Saharias were found to be illiterate. $4.6 \%$ of them could read and write. Few had

Table 1. Mean Age and Socio-Economic Characteristics of Subjects

\begin{tabular}{|l|l|}
\hline Variables & Mean \pm SD/ \% \\
\hline \hline Mean age (years) & \\
Males & $32.6 \pm 9.89$ \\
Females & $36.7 \pm 11.33$ \\
Income (Rupees per month) & \\
$<3000$ & $87.9 \%$ \\
$3001-5000$ & $6.6 \%$ \\
$>5000$ & $5.5 \%$ \\
Educational status & \\
Illiterate & $87.0 \%$ \\
Read and write & $4.6 \%$ \\
Up to primary & $3.5 \%$ \\
Up to higher sec & $4.9 \%$ \\
\hline
\end{tabular}

studied up to primary level $(3.5 \%)$ and $4.9 \%$ had studied up to higher secondary. More than $87 \%$ were earning the lowest.

Table 2 displays basic data of Saharias among three different groups classified on the basis of BMI. Stature and weight were found to be higher among males than their female counterparts. Normal weight group was found to be the tallest unlike underweight and overweight subjects.

Table 3 presents distribution of anthropometric variables among different groups of subjects based on BMI. All the skinfold thickness, upper arm circumference, trunk extremity ratio (TER) and grand mean thickness (GMT) were found to be highest among overweight and lowest among underweight subjects. All the skinfold thicknesses and GMT were found to be higher among females, whereas the TER and upper arm circumference were found to be higher among males.

Table 4 presents distribution of physiological variables among different groups of subjects based on BMI. All the females were found to have normal blood pressure. However, males in overweight category displayed prehypertension and hypertension. Muscular strength as assessed with the help of hand grip strength was found to be more among males as compared to females. The grip strength increased with BMI values among males. In both males and females the fat percentage was found to be highest in overweight subjects as compared to normal weight and underweight subjects.

Sexual dimorphism was clearly marked for majority of the body measurements for subjects in different nutritional status categories (Table 7).

Table 5 displays distribution of subjects according to nutritional status based on BMI. Nutritional status of Saharias of MP was found to be poor with a higher percentage of chronic energy deficient males and females. Among males some percent of overweight subjects were also noted. $62.3 \%$ females and $43.6 \%$ males were found to belong to normal weight category. Chronic energy deficiency (CED) was found to be much higher among males than the females. Percentage of overweight (BMI) was also found to be relatively higher among males unlike females. The differences between males and females for all the nutritional status categories were found to be statistically significant $(\mathrm{p}<0.001)$.

More Females $(76.0 \%)$ were found to be undernourished than males $(47.6 \%)$ as per the cut-off values of upper arm circumference (Table 6) and the differences were statistically significant $(<0.001)$.

\section{DISCUSSION}

Tribal populations are particularly vulnerable to malnutrition due to their traditional socio-cultural practices and low literacy level. The low socio-economic status of Saharia is quite apparent from their income and educational level. The impact of low socio-economic status is clearly evident in the prevalence of CED among males (48.8\%) and females (37.2\%). As per WHO [17], a CED of $40 \%$ or more exhibits a critical public health problem, and that between $20-39 \%$ exhibits a serious public health situation. A higher prevalence of CED as well as overweight among males in com- 
Table 2. Basic Data of Subjects as Per BMI Categories

\begin{tabular}{|c|c|c|c|c|c|c|}
\hline Variables & \multicolumn{2}{|c|}{ Underweight } & \multicolumn{2}{|c|}{ Normal Weight } & \multicolumn{2}{|c|}{ Overweight } \\
\hline \multirow[b]{2}{*}{ Stature (cm) } & (82) & (73) & (73) & (121) & (13) & (2) \\
\hline & $164.9 \pm 4.78$ & $152.0 \pm 7.61$ & $165.6 \pm 7.63$ & $152.6 \pm 4.48$ & $162.1 \pm 3.94$ & $149.0 \pm 0.0$ \\
\hline
\end{tabular}

CED III, CED II and CED I (WHO, 1995) have been clubbed as underweight category.

Table 3. Anthropometric Variables as Per BMI Categories

\begin{tabular}{|c|c|c|c|c|c|c|}
\hline \multirow[t]{3}{*}{ Variables } & \multicolumn{2}{|c|}{ Underweight } & \multicolumn{2}{|c|}{ Normal weight } & \multicolumn{2}{|c|}{ Overweight } \\
\hline & \multicolumn{2}{|c|}{ Mean \pm SD } & \multicolumn{2}{|c|}{ Mean \pm SD } & \multicolumn{2}{|c|}{ Mean \pm SD } \\
\hline & Males & Females & Males & Females & Males & Females \\
\hline Subscapular skin fold thickness (mm) & $8.7 \pm 2.14$ & $9.3 \pm 2.30$ & $10.1 \pm 4.29$ & $11.8 \pm 2.71$ & $16.4 \pm 1.38$ & $30.4 \pm 0$ \\
\hline Suprailiac skin fold thickness (mm) & $7.0 \pm 2.43$ & $7.8 \pm 2.84$ & $8.4 \pm 4.17$ & $9.0 \pm 3.27$ & $13.7 \pm 3.33$ & $21.8 \pm 0$ \\
\hline Calf posterior skin fold thickness (mm) & $7.7 \pm 3.15$ & $7.7 \pm 2.14$ & $8.8 \pm 4.65$ & $10.5 \pm 3.30$ & $11.5 \pm 3.81$ & $22.2 \pm 0.28$ \\
\hline Mid Upper arm circumference $(\mathrm{cm})$ & $20.7 \pm 1.31$ & $19.9 \pm 1.76$ & $24.2 \pm 1.79$ & $21.4 \pm 1.69$ & $27.6 \pm 2.25$ & $24.4 \pm 0$ \\
\hline Trunk extremity ratio & $1.4 \pm 0.20$ & $1.3 \pm 0.26$ & $1.5 \pm 0.40$ & $1.3 \pm 0.38$ & $1.6 \pm 0.35$ & $1.3 \pm 0.04$ \\
\hline GMT (mm) & $7.2 \pm 2.04$ & $7.7 \pm 2.04$ & $8.2 \pm 3.61$ & $9.6 \pm 2.11$ & $12.6 \pm 1.37$ & $22.7 \pm 1.61$ \\
\hline
\end{tabular}

CED III, CED II and CED I (WHO, 1995) have been clubbed as underweight category.

Table 4. Physiological Functions as Per BMI Categories

\begin{tabular}{|c|c|c|c|c|c|c|}
\hline \multirow[t]{2}{*}{ Variables } & \multirow{2}{*}{\multicolumn{2}{|c|}{$\begin{array}{c}\text { Underweight } \\
\text { Mean } \pm \text { SD }\end{array}$}} & \multirow{2}{*}{\multicolumn{2}{|c|}{$\begin{array}{c}\text { Normal weight } \\
\text { Mean } \pm \text { SD }\end{array}$}} & \multirow{2}{*}{\multicolumn{2}{|c|}{$\begin{array}{l}\text { Overweight } \\
\text { Mean } \pm \text { SD }^{\text {SD }}\end{array}$}} \\
\hline & & & & & & \\
\hline GSA (kg) & $29.2 \pm 5.18$ & $20.2 \pm 3.80$ & $35.9 \pm 6.38$ & $21.1 \pm 4.38$ & $36.3 \pm 5.87$ & $17.0 \pm 00$ \\
\hline Fat Percentage (\%) & $7.1 \pm 1.98$ & $15.5 \pm 7.52$ & $12.1 \pm 5.43$ & $23.2 \pm 3.39$ & $23.0 \pm 0.49$ & $37.0 \pm 00$ \\
\hline Diastolic Blood Pressure (mmHg) & $79.5 \pm 7.16$ & $72.2 \pm 6.8$ & $78.2 \pm 12.50$ & $73.8 \pm 6.54$ & $82.7 \pm 6.30$ & $74.0 \pm 00$ \\
\hline
\end{tabular}

CED III, CED II and CED I (WHO, 1995) have been clubbed as underweight category.

GSA is average grip strength of both the hands.

Table 5. Prevalence of CED, Normal Weight and Overweight Among Saharias

\begin{tabular}{|c|c|c|}
\hline BMI Category (WHO 1995) & Males (\%) & Females $(\%)$ \\
\hline \hline$<16.0$ CED III & 6.5 & 4.6 \\
\hline $16.0-16.9$ CED II & 8.9 & 21.4 \\
\hline $17.0-18.4$ CED I & 33.3 & 61.7 \\
\hline $18.5-24.9$ Normal & 43.5 & 1.0 \\
\hline$>25$ Overweight & 7.7 & 100 \\
\hline Total & 100 & 2 \\
\hline
\end{tabular}

$\chi^{2}=21.564 \mathrm{df}=4 \mathrm{p}<0.001$. 
Table 6. Prevalence of Malnutrition as per Mid Upper Arm Circumference (MUAC) Among Saharias

\begin{tabular}{|c|c|c|c|}
\hline Subjects & MUAC<22cm (\%) & MUAC =>22cm (\%) & Total \\
\hline \hline Males & 47.6 & 52.4 & 100 \\
\hline Females & 76.0 & 24.0 & 100 \\
\hline
\end{tabular}

$\chi 2=183.12 \mathrm{df}=1 \mathrm{p}<0.001$.

Table 7. Gender Differences for Various Body Measurements as Per Nutritional Status Categories

\begin{tabular}{|l|l|l|l|}
\hline Variable & $\begin{array}{l}\text { Underweight } \\
\text { Males vs. Females } \\
\text { 't' }\end{array}$ & $\begin{array}{l}\text { Normal weight } \\
\text { Males vs. Females } \\
\text { 't' }\end{array}$ & $\begin{array}{l}\text { Overweight } \\
\text { Males vs. Females } \\
\text { 't' }\end{array}$ \\
\hline \hline Stature & $12.53^{* * *}$ & $13.23^{* * *}$ & $11.99^{* * *}$ \\
Weight & $10.98^{* * *}$ & $10.91^{* * *}$ & $7.49^{* * *}$ \\
Subscapular skinfold thickness & 1.32 & $3.16^{* *}$ & $36.48^{* * *}$ \\
Suprailiac skinfold thickness & 1.72 & 1.15 & $8.78^{* * *}$ \\
Tricep skinfold thickness & $2.70^{* *}$ & $4.96^{* * *}$ & $35.66^{* * *}$ \\
Calf posterior skinfold thickness & 0.09 & $2.76^{* * *}$ & $9.92^{* * *}$ \\
Mid upper arm circumference & $2.73^{* *}$ & $10.41^{* * *}$ & $5.00^{* * *}$ \\
Grand mean thickness & $7.28^{* * *}$ & $2.87^{* *}$ & $8.39^{* * *}$ \\
Trunk extremity ratio & 0.63 & $3.83^{* * *}$ & $2.91^{*}$ \\
Fat\% & $4.11^{* * *}$ & $13.14^{* * *}$ & $38.55^{* * *}$ \\
Average grip strength & $12.52^{* * *}$ & $17.44^{* * *}$ & $11.86^{* * *}$ \\
SBP & $4.17^{* * *}$ & $2.63^{* *}$ & $5.13^{* * *}$ \\
DBP & $6.52^{* * *}$ & $4.09^{* * *}$ & $4.98^{* * * *}$ \\
\hline
\end{tabular}

${ }^{*} \mathrm{p}<0.05, * * \mathrm{p}<0.01, * * * \mathrm{p}<0.001$.

parison to their counterpart females, reflects the higher sensitivity in terms BMI to their environment.

The finding in the present study opens a debatable point about the role of different indices of nutritional status assessment. The prevalence of malnutrition on the basis of MUAC was more among Saharia females as compared to prevalence obtained by use of BMI standards. On comparing the socio-cultural norms and traditions among Saharias, it was found that the males are given preferential treatment for food and other necessities over females. More number of males are in contact with the mainstream population of the country. In light of these conditions we feel that MUAC is a relatively more sensitive index of assessing nutritional status. The Saharia males were found to be under critical situation and females under serious situation as per prevalence of CED classified as Public Health Problem by WHO [16]. Whatever index is taken it is clear that Saharias are malnourished, which is severely affecting their wage earning, thereby perpetuating a vicious cycle.

Another cause of concern is the finding of overweight cases more so among males as compared to females showing the coexistence of undernutrition and overnutritions. This population has to fight the menace of associated health problems at both ends of nutritional imbalance. Although the overweight cases are few but the rapidly changing lifestyle may increase the prevalence of such cases and the related comorbidities. Over the years, substantial changes have oc- curred among the Saharias such as settlement in towns due to jobs, more involvement in political scenario and consequently increase in mobility. These factors in conjunction with reduction in their traditional activities are bringing gradual changes in life style predisposing them to modern day health risk like overweight and obesity.

Distribution of fat in favor of trunk region has been found to be independently related to cardiovascular health problems [21, 22].The overweight Saharia males also showed higher centripetal fat as evident from TER and they were found to be more predisposed to hypertension.

The war Khasis, one of the subgroups of Khasi tribe of Meghalaya, North-East India was found to show high prevalence of CED [23] but it was less than that of Saharias of the present study. This seems a common characteristics of tribal population. The Saharia males were compared with adult males of another primitive tribe of high altitude in Himalayas namely Raji. The Rajis are a mountain dwelling primitive tribal population which is socially and economically the most underdeveloped tribal community of central Himalayas [3]. Rajis were physically very active and as per BMI categories 90 percent of them were CED but had well developed lungs and muscular strength. Saharias were taller and heavier than high altitude Rajis. Among Rajis none was found to be overweight unlike the Saharias of Madhya Pradesh. The Rajis were physically more active with more of healthy leanness and more muscular strength as compared to Saharia, 
thereby highlighting the adaptive role of higher level of habitual physical activity. The present study clearly shows the association of higher BMI with higher fat percentage and cardio-vascular health. The income and literacy were found to be directly related and both were found to influence the nutritional status.

\section{ACKNOWLEDGEMENTS}

The authors are thankful to all the subjects for their kind cooperation. SK is grateful to Dean Research, University of Delhi for providing financial assistance under the R\&D 1117 Research Funds.

\section{REFERENCES}

[1] Rao HD, Rao MK. Levels of malnutrition and socio-economic conditions among Maria Gonds. J Hum Ecol 1994; 5: 185-90.

[2] Tiwari DN. Growth and nutritional status of the Bharia-A primitive tribe of Madhya Pradesh. Coll Antropol 2007; 31(1): 95-101.

[3] Kapoor AK, Tyagi R, Kapoor Satwanti. Nutritional status and cardio-respiratory functions among adult Raji males, a hunter gatherer tribe of Indian Himalayas. Anthropol Sci 2009; 117(1): 1-7.

[4] Park K. Textbook of Preventive and Social Medicine. Jabalpur, India: Banarsidas Bhanot 2002.

[5] Biswas RK, Kapoor AK. Socio-cultural impact on maternal care among Saharia primitive tribe of Madhya Pradesh. J Region Health Care 2004; 9(1-2): 1-10

[6] Allison DB, Zhu SK, Plankey M, Fauth MS, Heo M. Differential association of BMI and adiposity with all cause mortality among men in the first and second National health and Nutritional Examination Surveys (NHANES I and NHANES II) follow up studies. Int J Obes 2002; 26: 410-6.

[7] Thakur D, Thakur DN. Tribe in central India 98-120 In: Thakur D, Thakur DN, Eds. Tribal life in India, New Delhi: Deep and Deep Publication 1994; vol.1.

[8] Tiwari DN. Primitive tribe of Madhya Pradesh. Government of India, Ministry of Home Affairs, Tribal Development Division: New Delhi 1984.

[9] Prabhu P. Social forestry: an adivasi viewpoint. In: Fernandes W, Kulkarni S, Eds. Towards A New Forest Policy: People's Right and
Environmental Needs. Indian Social Institute: New Delhi 1983; pp. 134-43.

[10] Singh KS. The Scheduled Tribes. Delhi: India Oxford University press 1994; vol. 3.

[11] Biswas RK. Demographic study of primitive tribe: a comparative framework. New Delhi: Saad Publication 2006.

[12] Biswas RK, Kapoor AK. Education and its effect on fertility and mortality differentials among a primitive tribe of Madhya Pradesh. Indian J Popul Educ 2003; 36-45.

[13] Sharma SP, Sharma JB. Tribal Demography. New Delhi: Radha Publications: 1999.

[14] Kshatriya GK. Ecology and Health with special Reference to Indian Tribe. In: Bhasin MK, Bhasin Veena, Eds. Man Environment Relationship, Human Ecology (Special Issue). New Delhi: Kamal Raj Enterprises 2002; pp. 229-45.

[15] Weiner JS, Lourie JA. Practical Human Biology. New York: Academic Press 1981.

[16] WHO. Physical status: the use and interpretation of anthropometry. Technical report series no. 854, World Health Organisation, Geneva 1995.

[17] Weisell RC. Body mass index as an indicator of obesity. Asia Pacific J Clin Nutr 2002; 11(suppl): S681-S4.

[18] WHO Obesity: Preventing and managing the global epidemic. Report of a WHO consultation. WHO Technical Report Series 894, Geneva: WHO 2000.

[19] James WPT, Mascie-Taylor CGN, Norgan NG, Bristrian BR, Shetty P, Ferro-Luzzi A. The value of arm circumference measurements in assessing chronic energy deficiency in Third World adults. Eur J Clin Nutr 1994; 48: 883-4.

[20] Joint National Committee (JNC) VII. Seventh report of the Joint National Committee on the prevention, detection, evaluation and treatment of high blood pressure. J Am Med Assoc 2003; 289: 2073-82.

[21] Huang B, Rodreiguez BL, Burchfield CM, Chyou Po-H, Curb JD, Sharp DS. Association of adiposity with prevalent coronary heart disease among elderly men: the Honololu heart program. Int J Obes 1997; 21(5): 340-8

[22] Tyagi R, Kapoor S, Kapoor AK. Body composition and fat distribution pattern of urban elderly females, Delhi, India. Coll Antropol 2005; 29(2): 493-8.

[23] Khongsdier R. Body mass index and morbidity in adult males of the War Khasi in Northeast India. Eur J Clin Nutr 2002; 56: 484-9.

(C) Kapoor et al.; Licensee Bentham Open.

This is an open access article licensed under the terms of the Creative Commons Attribution Non-Commercial License (http://creativecommons.org/licenses/by-nc/3.0/) which permits unrestricted, non-commercial use, distribution and reproduction in any medium, provided the work is properly cited. 